\title{
Preparedness of the teachers for Team-Based Learning: Liking, disliking and suggestions of faculty
}

\author{
Abdus Salam ${ }^{1 *}$, Siti Mariam Bujang ${ }^{1}$, Mohammad Arif Kamarudin ${ }^{1}$, Mohamad Nurman Yaman ${ }^{1}$, Harlina Halizah Siraj ${ }^{1}$, \\ Nabishah Mohamad ${ }^{1,2}$ \\ ${ }^{1}$ Department of Medical Education, ${ }^{2}$ Department of Physiolosy, Faculty of Medicine, UKM Medical Centre, Kuala Lumpur, Malaysia.
}

\section{ARTICLE INFO \\ Article history: \\ Received on: 14/11/2015 \\ Revised on: 09/12/2015 \\ Accepted on: 16/01/2016 \\ Available online: 30/03/2016}

Key words:

Team based learning, preparedness workshop,

perspectives of Faculty.

\begin{abstract}
Faculty development is an integral part of institutional development. This paper describes liking, disliking and suggestions of faculty members on a 2-days Team-Based Learning faculty training workshop, where 39 faculty members were attended. Participants liked the lively and informal discussions through which they got a new technique to teach students more interactively. However, they disliked too short demonstration and short notification given them to read pre-assigned material and suggested more workshops with more practical demonstration before its implementation. Faculty developers should address the needs of the faculty while organizing developmental workshop aimed to link between theory and practice for a sustainable development.
\end{abstract}

\section{INTRODUCTION}

Team based learning is an instructional strategy which implies active learning process to promote both the learning of factual material as well as higher-level cognitive skills (Thompson et al., 2007; Nieder et al., 2005). It was originally developed for business schools and other higher learning settings and currently being employed in various courses in medical and health professional education (Thompson et al., 2007; Hunt et al., 2003; Koles et al., 2005; Nieder et al., 2005).

It differs from problem-based learning (PBL) in that, there is no need for multiple faculty or rooms for TBL; the instructor need not have any experience in group process but must be a content-expert; since student learn how to be productive and collaborative in the process, they do not need any specific instruction in teamwork (Parmelee et al., 2012). Faculty are more engaged with the students in TBL than in traditional lecture or other small group approaches and they know quickly what their students are achieving (Nieder et al., 2005). There are four essential principles in TBL and the success depends when the faculty able

\footnotetext{
* Corresponding Author

Abdus Salam, Medical Education Department, Faculty of Medicine, Universiti Kebangsaan Malaysia (National University of Malaysia), Kuala Lumpur, Malaysia.Email: abdussalam.dr@gmail.com
}

to implement all these four principles. The essential principles are: (i) groups must be properly formed and managed, (ii) students must be made accountable for their individual and group work, (iii) group assignments must promote both learning and team development, and (iv) students must have frequent and timely feedback. When these principles are in place, groups of students evolve into cohesive learning teams (Michaelsen et al., 2004). In Medical faculty of University Kebangsaan Malaysia, TBL is a new method of teaching adapted to foster the teaching-learning among the medical students. Preparedness of teachers and their perceptions on a new method of teaching is very important for its successful implication. This paper determines the teachers' expression and liking, disliking and suggestions following a postworkshop evaluation on TBL training workshop. This paper may help to get thought on initiating TBL in an educational institution.

\section{MATERIALS AND METHODS}

This was a qualitative survey on TBL conducted at the end of a 2-days-TBL training workshop held at UKM Medical Centre in September 2014. It was attended by 39 faculty members from different disciplines of UKM medical centre.

The TBL training workshop was conducted through assigned pre-reading, application exercises, interactive lectures and video demonstration on TBL, and feedback. Medical education expertise faculty members facilitated the workshop. 
Day before begening of the workshop, faculties were provided an article on TBL to read on it. On day one of workshop after introductory session, there were hands on exercise on TBL which consisted of sitting of all participants in different small groups, performing individual readiness assurance test (RAT), group RAT and team activities. First, individual participants answered items on a RAT on TBL. After that, group members discussed and answered the items of same RAT in groups. Participants were familiarized with the basic concepts of TBL through interactive lectures. Facilitators guided the participants to discuss in groups and solve the items of RAT using their background reasoning. In the afternoon, video on TBL was demonstrated to enhance the participants' understanding on TBL concepts. On day two of workshop, one representative from each team presented and had shown how their PPT of lecture sessions can be converted into TBL session.

At the end of the workshop, feedback from the participants was obtained by distributing the open-ended questionnaire asking about "What did participants like in this workshop?", "What did participants dislike in this workshop?", "What is/are participants' suggestions to improve future TBL training workshop?". The questionnaire was then collected, compiled and thematic analysis was done.

\section{RESULTS}

Faculties' responses on their liking, disliking and suggestion to improve future TBL training workshop are shown in tables 1, 2 and 3 respectively. Faculty members participated in this workshop liked this new method of tutoring to teach more interactively and gained new insight with informal lively discussions through great team effort (Table 1). The main disliking was short notification about assigned pre-reading, short demonstrations and disturbance from the departmental activity/ work (Table 2). Frequent workshop with smaller group, workshop at outside work place, longer demonstrations with example from other centers and to involve more lecturers were the major suggestions (Table 3).

\section{DISCUSSION}

The curricular transition needs active participation of the faculty members and it would be difficult for the transition if the faculty feel challenged or unable to meet the expectation of the tutoring. This workshop showed positive influence to the faculty in their perception on TBL. This is expressed by their likeliness to this new method of teaching by saying that the workshop gave them 'a new way to teach medical students to make it more interactive, interesting and more students directed with lecturer guidance', 'a new insight on a more innovative way to teach more interactive me between students'(Table 1)

TBL is a transformative use of small groups learning in large classes (Parmelee et al., 2012). It enables the students at risk to fruitfully complete their course work and keep on track in their advancement toward graduation (Michaelsen and Sweet, 2008). Although most of the faculty members expressed to get new insight on more innovative way of teaching, still they disliked one basic step of not getting enough time for the reading as the materials were sent one day earlier (Table 2). In a study regarding the implementation of TBL in Oklahoma University, it was stated that around 30 pages of assigned materials were given to the students at least 2-3 days earlier, so enabling enough learning time for the session (Letassy et al., 2008). Thus, it is necessary to provide enough time for the preparation.

Faculty members also felt disturbed by the departmental activity even though they involved in the workshop. They were also worried about student commitments in TBL which is an integral part for the success of TBL (Table 2). It is evidenced that student accountability significantly increased with the implementation of TBL (Letassy et al., 2008). Study showed positive findings where faculty perceived that there were higher levels of student engagement and work as a team during class, increased class attendance and well preparedness to achieve the target knowledge (Allen et al., 2013). The reason behind active engagement in TBL was suggested possibly due to the good relationship among students in the team as well as due to their perception of individual contributions to the team's performance (Haidet et al., 2008).

Participants suggest, it would be better if they could have been exposed to the example from other centers especially medical schools, or get feedback from lecturers those who have conducted TBL. They preferred more lengthy video session and more frequent workshop with smaller groups for further clearer of their understanding.

They also suggest more of the lecturers need to have the opportunity to attend this type of workshop (Table 3). These suggestions are expected as this is a new method of teaching. Previous study on 10 medical schools in USA to review the progress and understand the factors affecting TBL showed many faculties initially interested for TBL but they wanted to see someone else to try it first to establish experience before they tried it themselves. Ongoing faculty training is thus very important to change the attitude and understanding on TBL. In the same study it was found that initially the faculty misunderstood the method. They relearned the method and better understanding leads to better work. They become more comfortable in time with the method. The first year of TBL in those medical schools were not perceived as good as the faculty was not comfortable with the method which was subsequently eliminated with the repeated use of TBL (Thompson et al., 2007).

Regarding time management, some liked two days is alright, some dislike saying those two days is too long and some suggest to compress into one and half days which could be better time management. Faculty also suggests doing the workshop outside the hospital or work place (Table 3), probably this suggestion is to avoid disturbance from the departmental activity during the time of workshop. 
Table 1: Faculties' responses on their liking in regards to TBL training workshop at UKM medical centre.

What faculties like?
Give a new way to teach medical students to make it more interactive, interesting and more students directed with lecturer guidance
Gain new knowledge, new concept, new technique, new insight on a more innovative way to teach more interactively with new challenge
Well planned and great team work by all who attended from various disciplines -made effort to work together
Hands on, get to network with colleagues from other department
Very informative, informal, lively discussion and clear explanation on the TBL concept
Just enough 2 days, to learn new method of teaching

Table 2: Faculties' responses on their disliking in regards to TBL training workshop at UKM medical centre.

The notification given to read through the TBL was with too short notice

Pre-reading material given one day before the workshop

Too big (multidiscipline) group

The lecture of TBL and video session is too short

Disturbance from the departmental activity / work, as to start a new concept need time and commitment

Many other uncertainties unanswered, until implementation of student commitment etc.

Too long duration

Table 3: Faculties' responses on suggestion to improve future TBL training workshop at UKM medical centre.

The notes to be given earlier and with some introductory slides on TBL

Faculties suggestion to improve

Need to repeat with smaller group and more frequently

Demonstration of TBL through video should be longer

Have a demonstration of the formation of the TBL

Do outside the hospital / work place

Will need to come to the clinical department to promote this new teaching

More of the lecturers need to have the opportunity to attend this type of workshop in order to push TBL through

It's not going to be easy to change current practice unless workshop is given and distributed to all respective lecturers

Must explained to the module based teaching

Demonstration of TBL session, e.g. example from other centers especially medical schools

Please show more example of other institution and get feedback from lecturers that have conducted TBL

May be to be able to see or be given examples of product of creativity of the instructor

Compress into one and half days could be better 'time' management

To produce a good human capital, realization of individuals' approaches from their own perspectives is crucial (Salam et al., 2014). It is necessary to prepare faculty comfortable before starting any new method of teaching. Academic vitality depends on faculty members' interest and expertise (Steinert, 2005) and learning is more likely to lead to changes in practice when needs assessments are conducted (Steinert, 2005; Grant, 2002) and faculty development activities done to fulfill the needs' of faculty. This evaluation provides the organiser an insight of the needs of faculty members in future developmental workshop aimed to link between theory and practice to ensure a sustainable organisational development.

\section{CONCLUSIONS}

TBL faculty preparedness workshop at UKM medical centre is found positive towards the new method of teaching. Faculty perceived that, TBL workshop prepared them for a new way to teach medical students to make it more interactive, interesting and more students directed with lecturer guidance. However, before starting a new teaching learning method, teachers need to be confident enough and hence, more practical demonstration is needed for the successful implementation of this new approach of teaching method. Future developmental workshop should aim to fulfill the needs of the faculty aimed to link between theory and practice for a sustainable organisational developmnt. Medical schools should use TBL as an educational tool in order to make the teaching more interactive and interesting aimed to increase learners' efficiency.

\section{CONFLICT OF INTEREST}

The authors declare that they have no conflict of interests.

\section{ACKNOWLEDGEMENT}

The authors would like to express their sincere thanks to the UKM ethics committee for this research grant PTS-2013-161.

\section{REFERENCES}

Allen RE, Copeland J, Franks AS, Karimi R, McCollum M, Riese DJ, Lin AYF. Team-based learning in US colleges and schools of Pharmacy. Am J Pharm Educ, 2013;77(66): 115.

Grant J. Learning needs assessment: assessing the need. British Medical Journal, 2002; 324:156-159.

Haidet P, Schneider V, Onady GM. 2008. Team based learning in Health Professions Education. In Michaelsen LK, Permelee DX, McMahon KK, Levine RE.(Eds). Team Based Learning for Health Professions Education. A Guide to Using Small Groups for Improving Learning. Virginia: Stylus Publishing, LLC. pp. 117-130.

Hunt DP, Haidet P, Coverdale JH, Richards B. The effect of using team learning in an evidenced based medicine course for medical students. Teac Learn Med, 2003; 15:131-139.

Koles P, Nelson S, Stolfi A, Parmelee D, Destephen D. Active learning in a pathology curriculum. Med educ, 2005; 39: 1045-1055.

Letassy NA, Fugate SE, Medina MS, Stroup JS, Britton ML. Using Team-Bases Learning in an Endocrine Module Across Two Campuses. Am J Pharm Educ, 2008; 72(5):103 
Michaelsen LK, and Sweet M. 2008. Fundamental Principles and Practices of Team Based Learning. In Michaelsen, L.K., Parmelee, D.X., McMahon, K.K., Levine, R.F. Team base learning for health professions education. Sterling, VA: Stylus. pp. 9-34.

Michaelsen LK, Knight AB, Fink LD. 2004. Team-Based Learning: A Transformative Use of Small Groups in College Teaching. Sterling, VA: Stylus. pp. 286.

Nieder GL, Parmelee DX, Stolfi A, Hudes PD. Team-Based Learning in a Medical Gross Anatomy and Embryology Course. Clin Anat, 2005; 18:56-63. DOI: 10.1002/ca.20040

Parmelee D, Michaelsen LK, Cook S, Hudes PD. (2012). Teambased learning: a practical guide: AMEE guide no. 65, 2012;34(5):e275e287. DOI:10.3109/0142159X.2012.651179.

Salam A, Akram A, Siti MB, Mohamad NY, Mohammad AK, Harlina HS, Nabishah M. Educational Environment in a Multicultural Society to Meet the Challenges of Diversity. J App Pharm Sci, 2014; 4 (09):110-113. DOI: 10.7324/JAPS.2014.40919.
Steinert Y. Staff development for clinical teachers. The Clinical Teacher, 2005; 2(2): 104-110.

Thompson BM, Schneider VF, Haidet P, Levine RE, McMahon KK, Perkowski LC, Richards BF. Team-based learning at ten medical schools: two years later. Medical Education, 2007; 41: 250-257. DOI:10.1111/j.1365-2929.2006.02684.x

\section{How to cite this article:}

Salam A, Bujang SM, Kamarudin MA, Yaman MN, Siraj HH, Mohamad N. Preparedness of the teachers for Team-Based Learning: Liking, disliking and suggestions of faculty. J App Pharm Sci, 2016; 6 (03): 077-080. 